\title{
Longitudinal Study of Physiologic Insulin Resistance and Metabolic Changes of Puberty
}

\author{
TAMARA S. HANNON, JANINE JANOSKY, AND SILVA A. ARSLANIAN
}

Division of Pediatric Endocrinology, Metabolism, and Diabetes Mellitus and Division of Weight Management and Wellness [T.S.H., S.A.A.], Children's Hospital of Pittsburgh, Pittsburgh, Pennsylvania 15213; Department of Family Medicine and Clinical Epidemiology [J.J.], University of Pittsburgh School of Medicine, Pittsburgh, Pennsylvania 15213

\begin{abstract}
Cross-sectional studies have shown that 1) adolescents are insulin resistant compared with prepubertal children and adults, 2) pubertal insulin resistance is likely mediated by growth hormone $(\mathrm{GH})$, and 3) pubertal insulin resistance is associated with increased fat oxidation and decreased glucose oxidation. The aim of this study was to assess the validity of these cross-sectional observations by performing a longitudinal study in normal children during the prepubertal and pubertal periods. Nine healthy, normal weight, prepubertal children underwent hyperinsulinemic-euglycemic and hyperglycemic clamp studies for evaluation of insulin sensitivity and insulin secretion. Children had repeat evaluations during puberty. Consistent with cross-sectional observations, this longitudinal study demonstrated that during puberty: 1) insulin sensitivity decreased by $\sim 50 \%, 2$ ) the decrease in insulin sensitivity was compensated by a doubling in insulin secretion, and 3) the decrease in insulin sensitivity was independent of changes in percentage of body fat. Puberty was associated with increased total body lipolysis and decreased glucose oxidation. A novel observation is the demonstration of $\sim 50 \%$ decrease in adiponectin levels at the pubertal time point. These metabolic changes are proposed to be partially mediated by increased GH secretion and are consistent with the Randle cycle of competition between glucose and fat oxidation. (Pediatr Res 60: 759-763, 2006)
\end{abstract}

$\mathrm{C}$ ross-sectional studies examining insulin resistance during puberty have revealed that 1) pubertal insulin resistance is physiologic, occurring with pubertal progression and resolving by the end of puberty (1);2) measures of adiposity do not completely explain physiologic pubertal insulin resistance (2); and 3) pubertal insulin resistance is associated with decreased peripheral insulin sensitivity and increased insulin secretion (3-6). We and others have shown that the pubertal increase in GH/insulin-like growth factor I (IGF-I) contributes to pubertal insulin resistance (7-9). The metabolic characteristics of pubertal insulin resistance are decreased glucose oxidation and decreased insulin-suppression of free fatty acid (FFA) oxidation $(3,10)$. According to the Randle cycle, increased fat

Received April 4, 2006; accepted July 7, 2006

Correspondence: Tamara S. Hannon, M.D., Children's Hospital of Pittsburgh, 3705 5th Avenue at DeSoto Street, 4A, Room 400, Pittsburgh, PA 15213; e-mail: tamara.hannon@chp.edu

This work was supported by U.S. Public Health Service Grants R01 HD27503, K24-HD01357, K23 RR17250-01, and M01-RR00084 from the National Center for Research Resources through the General Clinical Research Center at the Children's Hospital of Pittsburgh, and the Renziehausen Fund.

DOI: $10.1203 / 01 . p d r .0000246097 .73031 .27$ oxidation competes with glucose oxidation, contributing to decreased glucose uptake and insulin resistance (11-13). Our previous cross-sectional studies of the metabolic pathways responsible for pubertal insulin resistance are in agreement with the Randle theory (3).

Longitudinal studies of pubertal insulin resistance are scarce. Three longitudinal studies have reported on in vivo insulin sensitivity, using the frequently sampled i.v. glucose tolerance test, without information on the metabolism of insulin-sensitive fuels during the transition from prepuberty to puberty (14-16). Thus, the aim of this study was to investigate the longitudinal changes in in vivo insulin action and secretion, glucose and fat oxidation, total body lipolysis, and physical and hormonal characteristics in normal children during the prepubertal and pubertal periods. We hypothesized that puberty is associated with 1) decreased insulin sensitivity, with maintenance of glucose homeostasis via increased insulin secretion, and 2) an increase in the ratio of fat to glucose oxidation, mediated by increased GH/IGF-I. We further theorized that the decrease in insulin sensitivity during puberty correlates with the increase in GH/IGF-I and the ratio of fat to glucose oxidation.

\section{METHODS}

Study subjects. The studies were approved by the Human Rights Committee of Children's Hospital of Pittsburgh/Institutional Review Board, University of Pittsburgh, and parental informed consent and child assent were obtained for all subjects. Healthy, prepubertal participants were recruited from the surrounding community through local advertisements. Nine [body mass index $(\mathrm{BMI})<85$ th percentile] prepubertal children [six white girls, Tanner stage I for breast development and pubic hair, estradiol levels $0-5$ $\mathrm{pg} / \mathrm{mL}$; three boys (one black, two white), Tanner stage I for genital development and pubic hair, testosterone levels $7-14 \mathrm{ng} / \mathrm{dL}]$ were studied in the General Clinical Research Center (GCRC) at Children's Hospital of Pittsburgh. None of the participants were taking chronic medications, including contraceptive pills or had a chronic disease known to influence body composition or insulin action. All nine participants underwent all study evaluations twice, once while prepubertal and again during puberty. All subjects were in good health during both study periods as assessed by medical history, physical examination, normal glycosylated hemoglobin (HbA1C) values, and routine hematologic and biochemical tests. The mean interval between the prepubertal and pubertal studies for participants was $5.4 \pm 1.2 \mathrm{y}$ (range, 3-7 y). Pubertal development was assessed according to the criteria of Tanner by a single pediatric endocrinologist (Tanner stage IV-V for breast development and pubic hair in females, range of estradiol levels $18-159 \mathrm{pg} / \mathrm{mL}$; Tanner stage III-V for genital development and pubic hair in males, range of

Abbreviations: GCRC, General Clinical Research Center; $\mathbf{R}_{\mathbf{a}}$, rate of appearance 
Table 1. Physical, hormonal, and metabolic characteristics of subjects at baseline (prepuberty) and at puberty

\begin{tabular}{|c|c|c|}
\hline & $\begin{array}{l}\text { Prepuberty } \\
\quad(n=9)\end{array}$ & $\begin{array}{l}\text { Puberty } \\
(n=9)\end{array}$ \\
\hline Age, $y \neq$ & $9.8 \pm 0.4$ & $15.3 \pm 0.4$ \\
\hline Weight, kg & $31.8 \pm 1.3$ & $62.7 \pm 3.1$ \\
\hline Height, cm $\ddagger$ & $137.8 \pm 2.6$ & $167.2 \pm 3.0$ \\
\hline BMI percentile & $47.8 \pm 7.0$ & $62.2 \pm 10.4$ \\
\hline Fat-free mass, $\mathrm{kg} \ddagger$ & $23.7 \pm 0.9$ & $42.5 \pm 2.2$ \\
\hline Fat mass, $\mathrm{kg}^{*}$ & $6.0 \pm 0.7$ & $17.1 \pm 4.1$ \\
\hline$\%$ Body fat & $19.2 \pm 2.0$ & $26.1 \pm 5.2$ \\
\hline Visceral adipose tissue, $\mathrm{cm}^{2} *$ & $10.8 \pm 0.9$ & $31.8 \pm 6.2$ \\
\hline IGF-I, ng/mL $\dagger$ & $201.3 \pm 14.3$ & $330.7 \pm 31.3$ \\
\hline Glucose, mg/dL & $93.8 \pm 1.8$ & $95.4 \pm 1.5$ \\
\hline Insulin, $\mu \mathrm{U} / \mathrm{mL}^{*}$ & $12.6 \pm 0.9$ & $24.1 \pm 4.1$ \\
\hline C-peptide, $\mathrm{ng} / \mathrm{mL}^{*}$ & $1.01 \pm 0.12$ & $2.28 \pm 0.33$ \\
\hline $\begin{array}{l}\text { Fasting hepatic glucose production, } \\
\mathrm{mg} / \mathrm{kg} / \mathrm{min}^{*}\end{array}$ & $4.6 \pm 0.8$ & $2.6 \pm 0.3$ \\
\hline Leptin, $\mathrm{ng} / \mathrm{mL}^{*}$ & $7.5 \pm 1.4$ & $17.9 \pm 5.4$ \\
\hline Adiponectin, $\mu \mathrm{g} / \mathrm{mL} \dagger$ & $15.9 \pm 2.3$ & $7.5 \pm 1.2$ \\
\hline Cholesterol, $\mathrm{mg} / \mathrm{dL}{ }^{*}$ & $165 \pm 8$ & $146 \pm 10$ \\
\hline Triglycerides, $\mathrm{mg} / \mathrm{dL}$ & $91 \pm 14$ & $81 \pm 8$ \\
\hline $\mathrm{LDL}, \mathrm{mg} / \mathrm{dL}$ & $94 \pm 7$ & $88 \pm 10$ \\
\hline $\mathrm{HDL}, \mathrm{mg} / \mathrm{dL} *$ & $53 \pm 4$ & $43 \pm 2$ \\
\hline $\mathrm{VLDL}, \mathrm{mg} / \mathrm{dL}$ & $18 \pm 3$ & $16 \pm 2$ \\
\hline $\mathrm{LDL} / \mathrm{HDL}$ & $1.8 \pm 0.2$ & $2.2 \pm 0.3$ \\
\hline
\end{tabular}

$* p<0.05$.

$\dagger p<0.01$.

$\ddagger p<0.001$.

LDL, low-density lipoprotein; HDL, high-density lipoprotein; VLDL, very low density lipoprotein.

testosterone levels $637-781 \mathrm{ng} / \mathrm{dL}$ ). Baseline characteristics and characteristics at follow-up of the participants are presented in Table 1.

Metabolic studies. All evaluations were performed in the GCRC after a 10- to 12-h overnight fast. At both the prepubertal and pubertal time points, each subject was studied twice (1-3 wk apart), once during a 3-h hyperinsulinemic-euglycemic clamp to assess insulin sensitivity and once during a 2-h hyperglycemic clamp to assess insulin secretion, according to the methods originally described by DeFronzo et al. (17). For each study, two i.v. catheters were inserted, one in a forearm vein for administration of stable isotopes, insulin, and glucose, and the second in a dorsal contralateral hand vein for sampling of arterialized venous blood from the warmed hand.

Total-body lipolysis was measured at baseline after overnight fasting by the use of a primed $(1.2 \mu \mathrm{mol} / \mathrm{kg})$ constant rate $\left(0.08 \mu \mathrm{mol} \cdot \mathrm{kg}^{-1} \cdot \mathrm{min}^{-1}\right)$ infusion of $\left[{ }^{2} \mathrm{H}_{5}\right]$ glycerol (Isotec, Miamisburg, $\mathrm{OH}$ ), which was started $3 \mathrm{~h}$ before the clamp (3). Fasting hepatic glucose production was measured simultaneously with a primed $(2.8 \mu \mathrm{mol} / \mathrm{kg})$ constant infusion $(0.28$ $\left.\mu \mathrm{mol} \cdot \mathrm{kg}^{-1} \cdot \min ^{-1}\right)$ of $\left[6,6-{ }^{2} \mathrm{H}_{2}\right]$ glucose $(18)$. Insulin sensitivity was assessed during a $3-\mathrm{h} 40 \mathrm{mU} \cdot \mathrm{m}^{-2} \cdot \mathrm{min}^{-1}$ hyperinsulinemic-euglycemic clamp in conjunction with indirect calorimetry $(3,19,20)$. First- and secondphase insulin secretion was assessed during a 2-h hyperglycemic clamp (225 $\mathrm{mg} / \mathrm{dL})(3,20)$.

Body composition analysis. Body composition was determined by dualenergy x-ray absorptiometry (DEXA). Visceral adipose tissue $\left(\mathrm{cm}^{2}\right)$ was determined using a single-slice computed tomography scan at intervertebral space L4-5, as previously described (20).

Biochemical measurements. Plasma glucose was measured by the glucose oxidase method (Yellow Springs Instrument, Yellow Springs, OH). Plasma insulin concentration was determined by radioimmunoassay (RIA) (20). Plasma FFA levels were quantitated by an enzymatic colorimetric method with the use of the nonesterified fatty acid C test kit (Wako, Osaka, Japan) (10). IGF-I was measured by RIA after acid ethanol extraction (Nichols, San Juan Capistrano, CA). Plasma lipid levels were measured using the standards of the Centers for Disease Control and Prevention as described previously (19). Serum leptin was measured by double-antibody RIA using ${ }^{125}$ I-labeled human leptin as tracer and rabbit antihuman leptin antibodies (Linco, St. Louis, MO). Adiponectin was measured using a commercially available RIA kit (Linco Research) (21). Cpeptide determinations were performed at Esoterix Inc., (Calabasas Hills, CA) by immunochemiluminescent assay. Total and free testosterone, estradiol, and dehydroepiandrosterone sulfate were measured as described previously $(18-20,22)$.
Deuterium enrichment of glucose and glycerol in the plasma were determined on a Hewlett-Packard Co. 5971 mass spectrometer (Palo Alto, CA) coupled to a 5890 series II gas chromatograph as previously reported $(10,18)$. Plasma samples were deproteinized with methanol. Supernatants were dried in a vacuum centrifuge. The aldolnitrile pentaacetate derivative of glucose was analyzed for ${ }^{2} \mathrm{H}$ enrichment in the electron impact mode. Selective ion monitoring software was used to monitor the mass-to-charge ratio for $(\mathrm{m} / \mathrm{z})$ 200 and 202, reflecting unlabeled and labeled glucose. Pentafluoropropyl derivatives of glycerol were prepared by adding pentafluoropropionic anhydride and ethyl acetate to the dried samples. Selected ion monitoring software was used to monitor charge-to-mass ratio $(\mathrm{m} / \mathrm{z}) 367$ for $(M)$ and 372 for $(M+$ 5), representing unlabeled and ${ }^{2} \mathrm{H}_{5}$-labeled glycerol. Standard curves of known enrichments were performed with each assay.

Insulin sensitivity and secretion. Glucose turnover at baseline was calculated during the last $30 \mathrm{~min}$ of the fasting $\left[6,6-{ }^{2} \mathrm{H}_{2}\right]$ glucose infusion period according to steady-state tracer dilution equations as previously reported (18). Insulin-stimulated glucose disposal was calculated during the last $30 \mathrm{~min}$ of the euglycemic-hyperinsulinemic clamp to be equal to the rate of exogenous glucose infusion. Peripheral insulin sensitivity was calculated by dividing the glucose disposal rate by the steady-state clamp insulin level and multiplied by 100 (mg.kg fat-free mass ${ }^{-1} \cdot \mathrm{min}^{-1}$ per $\mu \mathrm{U} \cdot \mathrm{mL}^{-1}$ ). The glucose disposition index was calculated as the product of insulin sensitivity $\times$ first-phase insulin secretion (23). During the hyperglycemic clamp, the first-phase insulin concentration was calculated as the mean of five determinations every $2.5 \mathrm{~min}$ during the first 15 min of the clamp, and the second-phase concentration was calculated as the mean of eight determinations from 15-120 min (24).

Total-body lipolysis. The rate of appearance $\left(\mathrm{R}_{\mathrm{a}}\right)$ of endogenous glycerol in plasma was calculated during the last $30 \mathrm{~min}$ of the fasting period according to steady-state tracer dilution equations (3).

Glucose and fat oxidation. Basal and insulin-stimulated glucose and fat oxidation rates were calculated from indirect calorimetric data by averaging the data over the $30 \mathrm{~min}$ of measurements at baseline and at the end of the 3-h clamp study according to Frayn formulas (10). Glucose storage or nonoxidative glucose disposal during hyperinsulinemia was estimated by subtracting glucose oxidation from total glucose disposal.

Statistical analysis. Statistical analyses were performed using withinsubject changes and were assessed by a paired two-tailed $t$ test. Spearman correlation analysis was used, where appropriate, to examine bivariate relationships. Data are presented as means \pm SEM. A $p$ value of $\leq 0.05$ was considered statistically significant.

\section{RESULTS}

Physical, hormonal, and lipid profiles. The longitudinal physical, hormonal, and lipid profiles of the participants at the prepubertal to pubertal time points are summarized in Table 1. Fat mass, including visceral fat, and fat-free mass increased during puberty, as expected. Only one subject became overweight (BMI $\geq 95$ th percentile) during puberty. Overall, the mean BMI percentiles and percentages of body fat were not significantly different during the prepubertal and pubertal time points, especially after excluding this subject. Moreover, the paired sample correlation for the percentage of body fat at prepubertal and pubertal time points was significant $(r=$ $0.848, p=0.004)$. Fasting hepatic glucose production decreased, fasting insulin levels increased, whereas fasting glucose levels were unchanged during puberty. As expected, puberty was associated with an increase in IGF-I and leptin levels. Puberty was also associated with a decrease $(\sim 50 \%)$ in adiponectin levels and a decrease in total and high-density lipoprotein cholesterol, without significant changes in the remaining components of the lipid profile.

Fat metabolism. Total body lipolysis (glycerol $\mathrm{R}_{\mathrm{a}}$ ) was higher $\left(175 \pm 13\right.$ versus $\left.233 \pm 21 \mu \mathrm{mol} / \mathrm{m}^{2} / \mathrm{min}, p=0.028\right)$ during puberty (Fig. 1A). When corrected for fat mass, rates of lipolysis were not significantly higher during puberty (36.7 \pm 4.8 versus $42.6 \pm 8.8 \mu \mathrm{mol} / \mathrm{kg}$ fat mass $/ \mathrm{min}, p=0.47)$. The ratio of fat to glucose oxidation (FOX/GOX) increased by 
A.

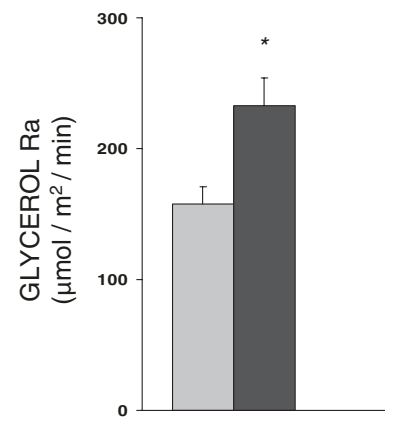

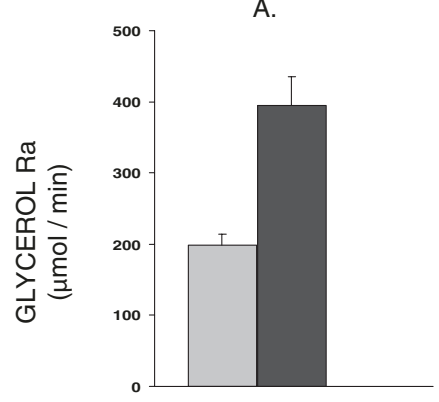

B.
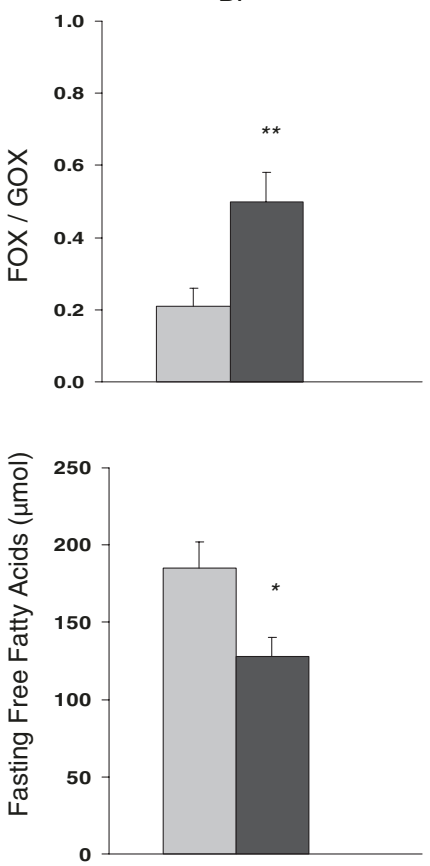

Figure 1. Rates of total body lipolysis (glycerol $\mathrm{R}_{\mathrm{a}}$ ) $(A)$ and substrate oxidation (FOX/GOX ratio) and FFA levels $(B)$ at the prepubertal (shaded columns) vs pubertal (filled columns) time points $(n=9)$. * $p<0.05$; ** $p<$ 0.01 .

$\sim 125 \%$ during puberty $(0.22 \pm 0.05$ versus $0.50 \pm 0.08, p=$ $0.005)$, with significantly lower plasma FFA levels $(\sim 31 \%)$ at the pubertal time point (Fig. 1B).

Glucose metabolism. Longitudinal changes in insulinmediated glucose metabolism among participants are summarized in Figs. 2 and 3. Insulin-stimulated total, oxidative, and nonoxidative glucose disposal decreased significantly during puberty (Fig. 2). During the hyperinsulinemic-euglycemic clamp, there were no significant differences between prepubertal and pubertal studies in steady-state clamp glucose $(101 \pm 0.8$ versus $101 \pm 0.4 \mathrm{mg} / \mathrm{dL}, p=0.989)$ or insulin $(102 \pm 5$ versus $148 \pm$ $20 \mu \mathrm{U} / \mathrm{mL}, p=0.059)$ concentrations. There was $\sim 50 \%$ decrease in insulin sensitivity at the pubertal time point, which was

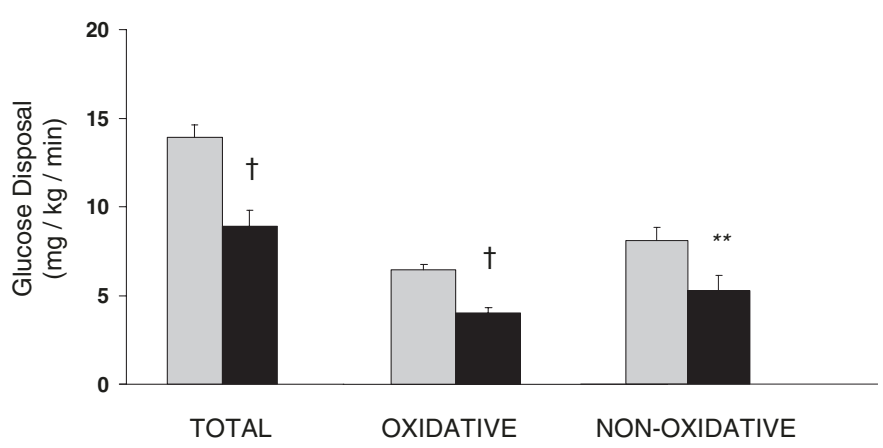

Figure 2. Insulin-stimulated glucose metabolism during the hyperinsulinemic-euglycemic clamp at the prepubertal (shaded columns) vs pubertal (filled columns) time points $(n=9)$. Total glucose disposal $=13.9 \pm 0.7$ vs $8.9 \pm$ $0.9 \mathrm{mg} / \mathrm{kg} / \mathrm{min}$. Nonoxidative glucose disposal $=7.7 \pm 0.7$ vs $5.0 \pm 0.8$ $\mathrm{mg} / \mathrm{kg} / \mathrm{min}$. Oxidative glucose disposal $=6.3 \pm 0.3$ vs $3.9 \pm 0.3 \mathrm{mg} / \mathrm{kg} / \mathrm{min}$. $* * p<0.01 ; \dagger p<0.001$. accompanied by a near doubling of first-phase insulin secretion, allowing for maintenance of the glucose disposition index (Fig. 3).

Correlations. IGF-I levels were negatively correlated with glucose oxidation $(r=-0.48, p=0.05)$, and positively correlated with total body lipolysis $(r=0.69, p=0.003)$ and fat oxidation $(r=0.47, p=0.05)$. There was no significant relationship between levels of sex steroids and measures of carbohydrate metabolism during puberty. In a multiple linear regression analysis with insulin sensitivity as the dependent variable and IGF-I, BMI percentile, and visceral adipose tissue as the independent variables $\left(R^{2}=0.44, p=0.05\right)$, the only significant contributor to the model was IGF-I, explaining $34 \%$ of the variance in insulin sensitivity (partial correlation of IGF-I $=-0.58, p=0.01$ ).

\section{DISCUSSION}

This is the first report of a longitudinal study of insulin sensitivity and insulin secretion that includes information on substrate utilization among children during the prepubertal and pubertal periods. Our results confirm and extend previous published longitudinal and cross-sectional studies examining developmental changes in insulin sensitivity. Consistent with cross-sectional observations, the present longitudinal study demonstrates that in otherwise healthy adolescents: 1) insulin sensitivity decreases by $\sim 50 \%$ during puberty; 2 ) the decrease in insulin sensitivity is compensated by a doubling of insulin secretion, maintaining the glucose disposition index and glucose homeostasis; and 3) the decrease in insulin sensitivity is not dependent on changes in the percentage of body fat. Moreover, and for the first time, the data show that during puberty basal rates of total body lipolysis increase significantly, with $\sim 125 \%$ increase in the ratio of fat to glucose oxidation.

In a previous longitudinal study of pubertal insulin resistance, Hoffman et al. (16) did not find a significant relationship between Tanner stage and insulin sensitivity, but did demonstrate significant relationships between insulin sensitivity and BMI and insulin sensitivity and peripheral GH action (IGF-I levels). In the Hoffman et al. study, participants ( $n=$ 24) were separated into individual Tanner stage groups, which is ideal, but may have limited the ability to detect significant associations between pubertal development and insulin resistance. Previous cross-sectional studies have shown that pubertal insulin resistance is present during all stages of puberty and returns to near prepubertal levels at Tanner stage V $(2,25)$. Our results demonstrate significant changes in insulin action and substrate utilization, despite grouping the subjects into only two groups (prepubertal and pubertal).

Our results indicating that puberty is associated with decreased insulin sensitivity and increased insulin secretion are consistent with results of previous longitudinal studies by Goran and Gower (15) and Ball et al. (14), both of which used the frequently sampled i.v. glucose tolerance test. These previous studies included larger numbers of participants $(n=60$ for the Goran and Gower study; $n=92$ for the Ball et al. study), consisting of a mixed population of white and black 

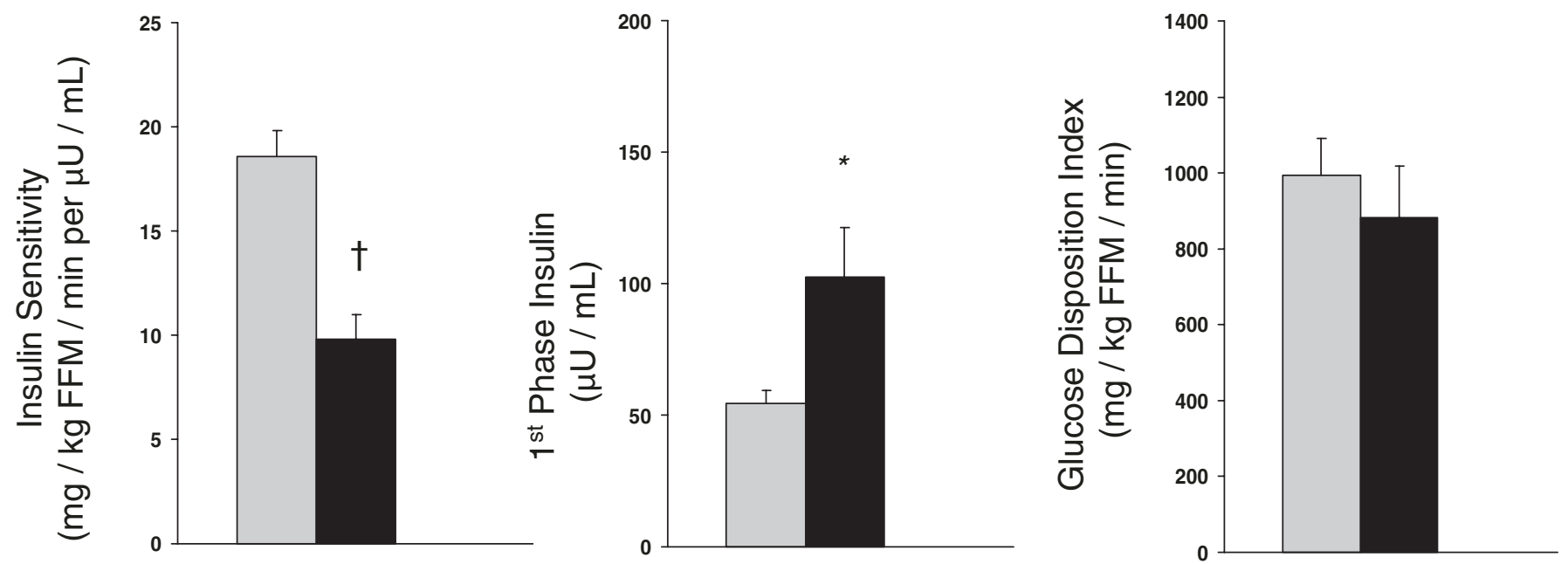

Figure 3. Insulin sensitivity calculated from the hyperinsulinemic-euglycemic clamp, first-phase insulin secretion during the hyperglycemic clamp, and glucose disposition index (insulin sensitivity $\times$ first-phase insulin) at the prepubertal (shaded columns) vs pubertal (filled columns) time points $(n=9)$. Insulin sensitivity $=$ $18.6 \pm 1.2 v s 10.0 \pm 1.2 \mathrm{mg} / \mathrm{kg} \mathrm{FFM} / \mathrm{min}$ per $\mu \mathrm{U} / \mathrm{mL}$. First-phase insulin secretion $=54 \pm 5$ vs $102 \pm 19 \mu \mathrm{U} / \mathrm{mL} . * p<0.05 ; \dagger p<0.001$.

subjects with variable percentages of body fat, including overweight prepubertal subjects. The Goran and Gower study showed that after controlling for measures of adiposity, children transitioning to puberty had decreased insulin sensitivity $(-32 \%)$, increased insulin secretion $(+30 \%)$, and a decreased glucose disposition index, suggesting pancreatic $\beta$-cell decompensation. The study by Ball et al. (14) confirmed the earlier findings and reported differences in the glucose disposition index among white and black children as they transitioned to puberty. Results of this study indicate that black children, but not white children, have a decreased glucose disposition indicative of declining pancreatic $\beta$-cell function during puberty. We have also previously shown that in highrisk children with a family history of type 2 diabetes mellitus, there is an impaired relationship between insulin action and pancreatic $\beta$-cell compensation even among those with normal glucose tolerance (26). In the present study, we found that despite a 50\% decrease in insulin sensitivity during puberty, the glucose disposition index was maintained via a compensatory increase in insulin secretion.

Consistent with previous cross-sectional studies, our data indicate that puberty-induced changes in insulin-stimulated fuel metabolism include reduced peripheral glucose uptake, reduced oxidative and nonoxidative glucose metabolism, and preservation of hepatic insulin sensitivity (decreased fasting hepatic glucose production) during puberty $(2,5,25)$. Previous studies have also shown that the ability of insulin to suppress hepatic glucose production is preserved during normal puberty (25). Increased total body lipolysis and decreased FFA levels during puberty were associated with decreased glucose oxidation. Previous cross-sectional studies have shown that total body lipolysis is higher in pubertal subjects than in prepubertal or adult subjects and those rates of lipolysis correlate positively with IGF-I levels (3). When lipolysis is expressed per unit of body weight or body fat, rates have been shown to be comparable between prepubertal and pubertal subjects $(3,27)$. Our data are in agreement with this and support the concept that physiologic pubertal insulin resistance affects glucose oxidation to a greater extent than fat oxidation, increasing the ratio of fat to glucose oxidation during puberty. This is consistent with our previous proposal that decreased glucose oxidation may be secondary to the Randle cycle of competition between fat and glucose oxidation $(3,10)$.

GH is known to increase total body lipolysis and fat oxidation $(28,29)$. Moreover, data from previous studies support the concept that the GH/IGF-I axis is an important contributor to pubertal insulin resistance $(8,9,30,31)$. It has been shown that children on exogenous GH therapy exhibit GH-induced changes in insulin-mediated glucose metabolism similar to those observed among pubertal children $(30,32)$. Our data support the concept that changes in the GH/IGF-I axis are associated with changes in insulin-sensitive fuel metabolism and contribute to pubertal insulin resistance; however, a causal relationship cannot be implied.

A novel observation from our data is the significant $(\sim 50 \%)$ decrease in adiponectin levels as children transitioned to puberty. We show here for the first time that adiponectin levels decrease in proportion to the decrease in insulin sensitivity during puberty. The decrease in adiponectin was not significantly correlated with change in the percentage of body fat $(r=0.65, p=0.16$ ), nor was it correlated with change in visceral fat $(r=-0.313, p=0.55)$. However, failure to detect a significant correlation here may be due to error because of the small number of participants in the study. Previous cross-sectional studies have shown that obese adolescents have $\sim 50 \%$ lower adiponectin than normal-weight peers, with adiponectin levels being inversely correlated with visceral adipose tissue (21) and positively correlated with insulin sensitivity and secretion $(33,34)$. Our data suggest that puberty alone may contribute to decreasing adiponectin levels; however, further study with larger numbers of participants is needed to verify this.

Our study is limited by a small subject population that included both males and females. Although the subject number was small, the prospective study design allowed for identical studies to be performed twice in the same subjects. 
Metabolic differences between the prepubertal period and the postpubertal period were highly significant, and results from this study contribute further to the knowledge base in the field of pediatric insulin resistance. In a complex longitudinal study of this nature, there is a risk that the study population would become more heterogeneous during the transition to puberty. In the current study, only one subject became overweight during the transition to puberty. Although pubertal insulin resistance is a normal physiologic process, it may contribute to a pathologic process in the presence of obesity and/or pancreatic $\beta$-cell dysfunction; thus, the risk of developing impaired glucose tolerance or type 2 diabetes mellitus is increased during adolescence $(14,33,35)$. This highlights the need for prevention/intervention of obesity during this most pivotal period of growth and development.

In conclusion, puberty was associated with a significant reduction in insulin sensitivity that was not explained by increased adiposity, with sufficient pancreatic $\beta$-cell compensation to maintain glucose homeostasis in this longitudinal study of healthy participants. Adiponectin levels were reduced in proportion to the reduction in insulin sensitivity. Puberty was also associated with increased total body lipolysis, decreased glucose oxidation, and increased ratio of fat to glucose oxidation. These changes are proposed to be partially mediated by GH/IGF-I and are consistent with the Randle cycle of competition between glucose and fat oxidation.

Acknowledgments. These studies would not have been possible without the nurses and staff of the General Clinical Research Center, recruitment efforts of Lynnette Orlansky and Sandy Stange, and the commitment of the study volunteers and their parents.

\section{REFERENCES}

1. Amiel SA, Sherwin RS, Simonson DC, Lauritano AA, Tamborlane WV 1986 Impaired insulin action in puberty. A contributing factor to poor glycemic control in adolescents with diabetes. N Engl J Med 315:215-219

2. Moran A, Jacobs DR Jr, Steinberger J, Hong CP, Prineas R, Luepker R, Sinaiko AR 1999 Insulin resistance during puberty: results from clamp studies in 357 children. Diabetes 48:2039-2044

3. Arslanian SA, Kalhan SC 1994 Correlations between fatty acid and glucose metabolism. Potential explanation of insulin resistance of puberty. Diabetes 43:908-914

4. Caprio S 1999 Insulin: the other anabolic hormone of puberty. Acta Paediatr Suppl 88:84-87

5. Caprio S, Cline G, Boulware S, Permanente C, Shulman GI, Sherwin RS, Tamborlane WV 1994 Effects of puberty and diabetes on metabolism of insulin-sensitive fuels. Am J Physiol 266:E885-E891

6. Caprio S, Plewe G, Diamond MP, Simonson DC, Boulware SD, Sherwin RS, Tamborlane WV 1989 Increased insulin secretion in puberty: a compensatory response to reductions in insulin sensitivity. J Pediatr 114:963-967

7. Arslanian S, Suprasongsin C 1997 Testosterone treatment in adolescents with delayed puberty: changes in body composition, protein, fat, and glucose metabolism. J Clin Endocrinol Metab 82:3213-3220

8. Moran A, Jacobs DR Jr, Steinberger J, Cohen P, Hong CP, Prineas R, Sinaiko AR 2002 Association between the insulin resistance of puberty and the insulin-like growth factor-I/growth hormone axis. J Clin Endocrinol Metab 87:4817-4820
9. Saad RJ, Keenan BS, Danadian K, Lewy VD, Arslanian SA 2001 Dihydrotestosterone treatment in adolescents with delayed puberty: does it explain insulin resistance of puberty? J Clin Endocrinol Metab 86:4881-4886

10. Arslanian S, Suprasongsin C 1997 Glucose-fatty acid interactions in prepubertal and pubertal children: effects of lipid infusion. Am J Physiol 272:E523-E529

11. Randle PJ 1998 Regulatory interactions between lipids and carbohydrates: the glucose fatty acid cycle after 35 years. Diabetes Metab Rev 14:263-283

12. Randle PJ, Garland PB, Hales CN, Newsholme EA 1963 The glucose fatty-acid cycle: its role in insulin sensitivity and the metabolic disturbances of diabetes mellitus. Lancet 1:785-789

13. Randle PJ, Priestman DA, Mistry S, Halsall A 1994 Mechanisms modifying glucose oxidation in diabetes mellitus. Diabetologia 37:S155-S161

14. Ball GD, Huang TT, Gower BA, Cruz ML, Shaibi GQ, Weigensberg MJ, Goran MI 2006 Longitudinal changes in insulin sensitivity, insulin secretion, and beta-cell function during puberty. J Pediatr 148:16-22

15. Goran MI, Gower BA 2001 Longitudinal study on pubertal insulin resistance. Diabetes 50:2444-2450

16. Hoffman RP, Vicini P, Sivitz WI, Cobelli C 2000 Pubertal adolescent male-female differences in insulin sensitivity and glucose effectiveness determined by the one compartment minimal model. Pediatr Res 48:384-388

17. DeFronzo RA, Tobin JD, Andres R 1979 Glucose clamp technique: a method for quantifying insulin secretion and resistance. Am J Physiol 237:E214-E223

18. Danadian K, Balasekaran G, Lewy V, Meza MP, Robertson R, Arslanian SA 1999 Insulin sensitivity in African-American children with and without family history of type 2 diabetes. Diabetes Care 22:1325-1329

19. Arslanian SA, Lewy VD, Danadian K 2001 Glucose intolerance in obese adolescents with polycystic ovary syndrome: roles of insulin resistance and beta-cell dysfunction and risk of cardiovascular disease. J Clin Endocrinol Metab 86:66-71

20. Arslanian SA, Saad R, Lewy V, Danadian K, Janosky J 2002 Hyperinsulinemia in African-American children: decreased insulin clearance and increased insulin secretion and its relationship to insulin sensitivity. Diabetes 51:3014-3019

21. Bacha F, Saad R, Gungor N, Arslanian SA 2004 Adiponectin in youth: relationship to visceral adiposity, insulin sensitivity, and beta-cell function. Diabetes Care 27:547-552

22. Lewy VD, Danadian K, Witchel SF, Arslanian S 2001 Early metabolic abnormalities in adolescent girls with polycystic ovarian syndrome. J Pediatr 138:38-44

23. Kahn SE, Prigeon RL, McCulloch DK, Boyko EJ, Bergman RN, Schwartz MW, Neifing JL, Ward WK, Beard JC, Palmer JP 1993 Quantification of the relationship between insulin sensitivity and beta-cell function in human subjects. Evidence for a hyperbolic function. Diabetes 42:1663-1672

24. Arslanian S, Suprasongsin C 1996 Differences in the in vivo insulin secretion and sensitivity of healthy black versus white adolescents. J Pediatr 129:440-443

25. Amiel SA, Caprio S, Sherwin RS, Plewe G, Haymond MW, Tamborlane WV 1991 Insulin resistance of puberty: a defect restricted to peripheral glucose metabolism. J Clin Endocrinol Metab 72:277-282

26. Arslanian SA, Bacha F, Saad R, Gungor N 2005 Family history of type 2 diabetes is associated with decreased insulin sensitivity and an impaired balance between insulin sensitivity and insulin secretion in white youth. Diabetes Care 28:115-119

27. Robinson C, Tamborlane WV, Maggs DG, Enoksson S, Sherwin RS, Silver D, Shulman GI, Caprio S 1998 Effect of insulin on glycerol production in obese adolescents. Am J Physiol 274:E737-E743

28. Mauras N, O'Brien KO, Welch S, Rini A, Helgeson K, Vieira NE, Yergey AL 2000 Insulin-like growth factor I and growth hormone $(\mathrm{GH})$ treatment in $\mathrm{GH}$-deficient humans: differential effects on protein, glucose, lipid, and calcium metabolism. J Clin Endocrinol Metab 85:1686-1694

29. Norrelund H, Vahl N, Juul A, Moller N, Alberti KG, Skakkebaek NE, Christiansen JS, Jorgensen JO 2000 Continuation of growth hormone $(\mathrm{GH})$ therapy in GHdeficient patients during transition from childhood to adulthood: impact on insulin sensitivity and substrate metabolism. J Clin Endocrinol Metab 85:1912-1917

30. Caprio S, Boulware D, Tamborlane V 1992 Growth hormone and insulin interactions. Horm Res 38:47-49

31. Cook JS, Hoffman RP, Stene MA, Hansen JR 1993 Effects of maturational stage on insulin sensitivity during puberty. J Clin Endocrinol Metab 77:725-730

32. Arslanian S, Kalhan S 1992 Effects of growth hormone releasing hormone on insulin action and insulin secretion in a hypopituitary patient evaluated by the clamp technique. Acta Endocrinol (Copenh) 127:93-96

33. Gungor N, Bacha F, Saad R, Janosky J, Arslanian S 2005 Youth type 2 diabetes: insulin resistance, beta-cell failure, or both? Diabetes Care 28:638-644

34. Weiss R, Taksali SE, Dufour S, Yeckel CW, Papademetris X, Cline G, Tamborlane WV, Dziura J, Shulman GI, Caprio S 2005 The "obese insulin-sensitive" adolescent: importance of adiponectin and lipid partitioning. J Clin Endocrinol Metab 90:37313737

35. Klein DJ, Aronson Friedman L, Harlan WR, Barton BA, Schreiber GB, Cohen RM, Harlan LC, Morrison JA 2004 Obesity and the development of insulin resistance and impaired fasting glucose in black and white adolescent girls: a longitudinal study. Diabetes Care 27:378-383 